\title{
Evaluasi Saluran Drainase di Perumahan Alam Sinar Sari Kabupaten Bogor
}

\author{
(Drainage System Evaluation in Alam Sinar Sari Residence Bogor Province West Java)
}

\author{
Fahri Ekananda ${ }^{1}$, Nora Herdiana Pandjaitan ${ }^{{ }^{*}}$, dan Maulana Ibrahim Rau ${ }^{1}$ \\ ${ }^{1}$ Departemen Teknik Sipil dan Lingkungan, Fakultas Teknologi Pertanian, Institut Pertanian Bogor. \\ Jl. Raya Dramaga, Kampus IPB Dramaga, PO BOX 220, Bogor, Jawa Barat Indonesia \\ *Penulis korespondensi: norahp@apps.ipb.ac.id
}

Disetujui: 20 Juni 2019

\begin{abstract}
Drainage system is one of the important infrastructure components to drain runoff from rainfall. The purpose of this research were to identify the condition of existing drainage system in Alam Sinar Sari Residence, to analyze the discharge using EPA SWMM 5.1 application, and to analyze the suitability of existing drainage system with its runoff. The research was conducted since March 2018 on Alam Sinar Sari Residence which is located in Cibeureum Petir, with the total area of 15 ha. Based on analysis and statistic test, the acceptable distribution model is Log Pearson III model with 5 year return period. The rainfall designed was $175.86 \mathrm{~mm}$. Based on simulation done using SWMM 5.1, the actual debit of conduit C76 were bigger than its planned debit and should be re-evaluated. Conduit $C 76$ had dimension of depth of $0.31 \mathrm{~m}$ and width of $0.34 \mathrm{~m}$. Based on simulation the discharge in C76 of $0.088 \mathrm{~m}^{3} / \mathrm{s}$ was bigger than the planned debit which was only $0.069 \mathrm{~m}^{3} / \mathrm{s}$. After evaluation, conduit C76 should undergone changes of width dimension from $0.34 \mathrm{~m}$ to $0.50 \mathrm{~m}$ to be able to hold runoff.
\end{abstract}

Keywords : designed rainfall, drainage, EPA SWMM 5.1, runoff

\section{PENDAHULUAN}

Saluran drainase merupakan salah satu komponen infrastruktur yang penting untuk menyalurkan kelebihan air. Meningkatnya limpasan karena berkurangnya daerah resapan air dapat diatasi dengan pembangunan saluran drainase yang memadai, yang dapat mengalirkan kelebihan air. Saat ini keberadaan sistem drainase merupakan salah satu penilaian infrastruktur perkotaan yang sangat penting. Kualitas manajemen suatu kota dapat dilihat dari kualitas sistem drainase yang ada. Sistem jaringan drainase perkotaan umumnya dibagi atas 2 bagian, yaitu sistem drainase makro dan sistem drainase mikro (Dewi et al. 2013). Saluran drainase yang buruk dapat menimbulkan berbagai masalah akibat dari genangan air atau banjir, seperti rusaknya lapisan struktur jalan yang akan menghambat lalu lintas dan aktivitas masyarakat (Dewi et al. 2013).

Beberapa penelitian telah menunjukkan bahwa ketika hujan tiba sering terjadi genangan yang disebabkan karena tidak berfungsinya saluran drainase dengan optimal (Tangkudung et al. 2013). Selain karena masalah sedimentasi, kondisi saluran yang rusak juga menjadi salah satu penyebab terjadinya genangan (Luciana et al. 2013). Oleh karena itu setiap perkembangan suatu daerah harus diikuti dengan evaluasi saluran drainase secara menyeluruh, tidak hanya pada lokasi pengembangan, tetapi juga daerah sekitarnya yang terpengaruh. Perumahan Alam Sinar Sari merupakan kompleks perumahan di daerah Cibeureum Petir, Dramaga yang akan mengalami genangan di jalan-jalannya ketika terjadi hujan, terutama hujan dengan intensitas yang cukup besar. 
Untuk itu perlu dilakukan penelitian mengenai besarnya limpasan yang terjadi dan kesesuaiannya dengan saluran drainase yang tersedia. Salah satu cara yang dapat digunakan adalah pemodelan menggunakan EPA SWMM 5.1. Model ini banyak digunakan untuk menganalisis permasalahan limpasan di daerah perkotaan.

\section{METODOLOGI}

Langkah awal dari penelitian ini adalah mencari dan menentukan gagasan atau ide penelitian yang dilanjutkan dengan identifikasi masalah dan tujuan penelitian, kemudian studi literatur dan studi lapangan.
Setelah itu, dilanjutkan dengan pengumpulan data. Langkah berikutnya adalah pengolahan data, kemudian dilakukan analisis data. Langkah-langkah penelitian disajikan dalam Gambar 1 .

Pengambilan data primer seperti pengukuran besar limpasan dan debit aliran pada saluran drainase dilakukan di Perumahan Alam Sinar Sari, Cibeureum, Dramaga, Kabupaten Bogor, Jawa Barat. Luas dari perumahan ini sendiri adalah 15 ha. Berdasarkan rencana pembangunan, perumahan ini mampu menampung sebanyak 360 KK. Analisis data dilaksanakan di Departemen Teknik Sipil dan Lingkungan Institut Pertanian Bogor.

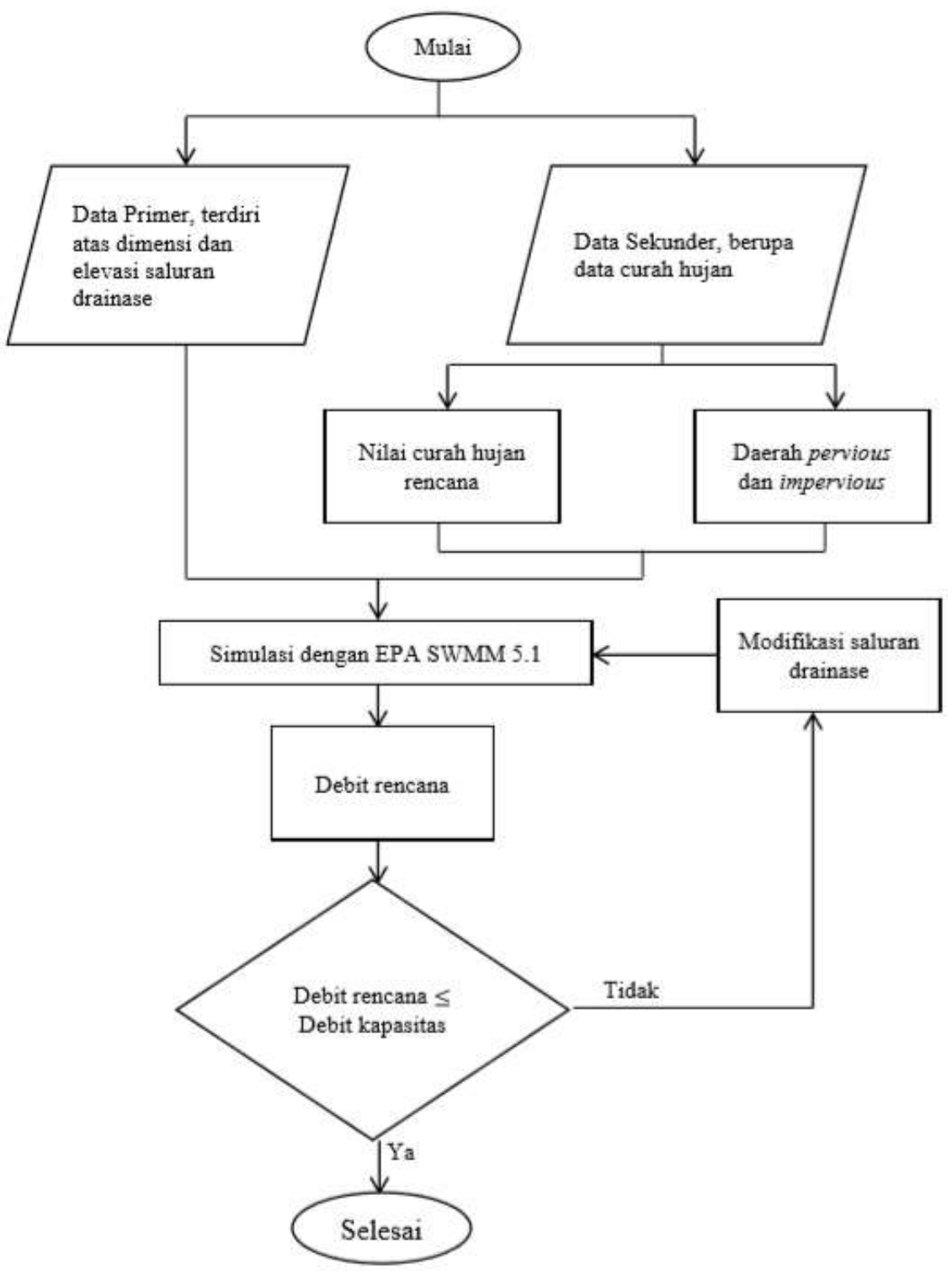

Gambar 1 Bagan alir penelitian 
Peralatan yang digunakan dalam penelitian ini antara lain seperangkat komputer dengan perangkat lunak EPA SWMM 5.1, pita ukur $50 \mathrm{~m}$, alat tulis, kalkulator, auto level, target rod, dan kompas. Bahan yang digunakan berupa data primer dan data sekunder. Data primer bersumber dari observasi lapangan dan pengukuran secara langsung di lapangan yang mencakup data karakteristik dan dimensi saluran drainase di perumahan Alam Sinar Sari, Cibeureum, Dramaga, Kabupaten Bogor, Jawa Barat. Data sekunder yang digunakan berupa data curah hujan harian maksimum selama 10 tahun di daerah Kabupaten Bogor, peta masterplan perumahan dan peta topografi.

Pengolahan data dilakukan dengan menggunakan data primer dan data sekunder. Data perimer yang digunakan dalam membuat permodelan saluran drainase yaitu kondisi eksisting jaringan drainase yang meliputi jenis saluran, panjang saluran, lebar saluran, kedalaman saluran, elevasi saluran, dan batas daerah tangkapan air untuk setiap subcatchment. Data sekunder yang digunakan meliputi data curah hujan harian, peta tutupan lahan, dan peta lokasi penelitian.

Dalam simulasi permodelan data-data yang digunakan antara lain:

\section{Rain Gage}

Rain Gage dalam program SWMM merupakan data penyedia curah hujan yang digunakan untuk satu atau lebih subcatchment. Data curah hujan didefinisikan sebagai time series pada software. Data curah hujan pada rain gage didapat dari hasil perhitungan curah hujan rencana dengan menggunakan analisisfrekuensi distribusi probalitas.

\section{Subcatchment}

Subcatchment merupakan daerah topogradi dan sistem drainase yang mengalirkan langsung aliran permukaan menuju suatu titik aliran outlet. Parameter subcatchment yang digunakan untuk permodelan software EPA SWMM yaitu luas subcatchment, presentase kemiringan subcathcment, panjang pengaliran, outlet, rain gauge, presentase luas daerah kedap air dan presentase dari impervious area tanpa depression storage. Pada subcatchment terdapat dua macam jenis area, yaitu impervious (kedap air) dan pervious (dapat dilalui air). Pada daerah impervious terdiri dari dua daerah yaitu depression storage dan non depression storage. Nilai depression storage dapat dilihat pada Tabel 1 (Rossman 2004).

Tabel 1 Nilai depression storage

\begin{tabular}{lc}
\hline Spesifikasi lahan & Depression storage $(\mathrm{mm})$ \\
\hline Permukaan Tanah & $1.27-2.54$ \\
Rumput & $2.54-5.08$ \\
Padang rumput & 0.508 \\
Hutan serasah & 0.762 \\
\hline
\end{tabular}

Metode perhitungan infiltrasi pada pervious area menggunakan metode Horton seperti pada persamaan (1) (Rossman 2004). Untuk nilai infiltrasi dari kondisi tanah memiliki dua nilai yaitu nilai infiltrasi maksimum Tabel 2 dan nilai infiltrasi minimum Tabel 3 (Rossman 2004). Sementara itu, untuk debit outflow dari limpasan subcatchment dihitung dengan persamaan Manning yaitu persamaan (2) dan (3) (Babbit 1969).

$F p=F c+(F o-F c) e-{ }^{k t}$

Keterangan:

$\mathrm{Fp}=$ angka infiltrasi dalam tanah $(\mathrm{mm} / \mathrm{jam})$

Fo $=$ nilai infiltrasi maksimum $(\mathrm{mm} / \mathrm{jam})$ (Tabel 3)

$\mathrm{Fc}=$ nilai infiltrasi minimum $(\mathrm{mm} / \mathrm{jam})$ (Tabel 1)

$\mathrm{k}=$ koefisien penurunan head ( $1 /$ det $)$ $\mathrm{t}=$ lama hujan (det) 
Tabel 2 Nilai infiltrasi maksimum pada berbagai kondisi tanah

\begin{tabular}{lll}
\hline \multicolumn{1}{c}{ Kondisi Tanah } & \multicolumn{1}{c}{ Jenis Tanah } & Nilai Infiltrasi (mm/jam) \\
\hline 1. Kering dengan sedikit atau & Tanah berpasir & 5 \\
tidak ada tumbuhan & Tanah lempung & 3 \\
& Tanah liat & 1 \\
2. Kering dengan tumbuhan & Tanah berpasir & 10 \\
& Tanah lempung & 6 \\
& Tanah liat & 2 \\
3. Tanah lembab & Tanah berpasir & 1.25 \\
& Tanah lempung & 1 \\
& Tanah liat & 0.33 \\
\hline
\end{tabular}

Tabel 3 Nilai infiltrasi minimum pada berbagai jenis tanah

\begin{tabular}{clc}
\hline Kel & \multicolumn{1}{c}{ Pengertian } & $\begin{array}{c}\text { Infiltrasi minimum } \\
\text { (mm/jam) }\end{array}$ \\
\hline A & $\begin{array}{l}\text { Potensi limpasan yang rendah. Tanah mempunyai tingkat } \\
\text { infiltrasi yang tinggi meskipun ketika tergenang dan }\end{array}$ & $>0.45$ \\
& $\begin{array}{l}\text { kedalaman genangan yang tinggi, pengeringan/ } \\
\text { penyerapan baik unsur pasir dan batuan. } \\
\text { Banah yang mempunyai tingkat infiltrasi biasa/ medium } \\
\text { ketika tergenang dan mempunyai tingkat kedalaman } \\
\text { genangan medium, pengeringan dengan keadaan biasa } \\
\text { didapat dari moderately fine to moderately coarse }\end{array}$ & $0.30-0.15$ \\
C $\quad \begin{array}{l}\text { Tanah mempunyai tingkat infiltrasi rendah jika lapisan } \\
\text { tanah untuk pengaliran air dengan tingkat tekstur bias ke } \\
\text { tekstur baik. Contoh lempung, pasir bermalau }\end{array}$ & $0.15-0.05$ \\
D $\begin{array}{l}\text { Potensi limpasan yang tinggi. Tanah mempunyai tingkat } \\
\text { infiltrasi rendah ketika tergenang }\end{array}$ & $0.05-0.00$ \\
\hline
\end{tabular}

3. Conduit

Conduit merupakan pipa atau saluran yang menyalurkan air dari satu node ke node yang lain. Bentuk melintang conduit dapat dipilih dari beberapa macam bentuk standar pada EPA SWMM 5.1. EPA SWMM 5.1 menggunakan persamaan Manning untuk menghitung debit pada conduit (Rossman 2004).

\section{Junction}

Junction adalah node-node sistem drainase yang berfungsi untuk menggabungkan satu saluran dengan saluran yang lain. Secara fisik, junction dapat menunjukan pertemuan dua saluran atau sambungan pipa. Outfall node adalah titik pemberhentian dari sistem drainase yang digunakan untuk menentukan batas hilir (downstream). Debit outflow pada saluran dihitung dengan persamaan Manning seperti pada persamaan (2) dan persamaan

(Hasmar 2011).

$v=\frac{1}{R} R s^{\frac{3}{2}} \frac{1}{f^{2}}$

$Q=v A$

Keterangan:

$\mathrm{v}=$ kecepatan aliran air di saluran $(\mathrm{m} / \mathrm{det})$

$\mathrm{n}=$ koefisien kekasaran dinding

$\mathrm{Rs}=$ jari - jari hidrolik $(\mathrm{m})$

$\mathrm{I}=$ kemiringą saluran

$\mathrm{Q}=\operatorname{debit}\left(\mathrm{m}^{3} / \mathrm{det}\right)$

$\mathrm{A}=$ luas penampang saluran

Analisis data dilakukan dengan beberapa tahap sebagai berikut.

1. Daerah Pervious dan Impervious

Analisis ini dilakukan dengan ground check untuk melihat daerah yang dapat dilalui 
air untuk infiltrasi (pervious) dan daerah yang tidak melewatkan air (impervious). Kemudian dapat dihitung persentase luas daerah previous dan impervious untuk setiap subcatchment sebagai nilai input data dalam subcatchment.

\section{Nilai Curah Hujan Rencana}

Nilai curah hujan rencana merupakan nilai input yang berupa time series. Analisis frekuensi untuk mendapatkan nilai curah hujan rencana dilakukan dengan menggunakan teori probability distribution yang meliputi Distribus Normal, Distribusi Log Normal, Distribusi Log Person III, dan Distribusi Gumbel. Selanjutnya, penentuan jenis distribusi yang digunakan akan dilakukan dengan uji kecocokan berdasarkan uji Chi Kuadrat. Nilai chi kuadrat adalah nilai kuadrat, sehingga nilai chi kuadrat selalu positif dengan bentuk distribusi chi kuadrat yang tergantung dari derajat bebas. Metode chi kuadrat menggunakan data nominal, data tersebut diperoleh dari hasil menghitung. Besarnya nilai chi kuadrat bukan merupakan ukuran derajat hubungan atau perbedaan.

\section{Model SWMM}

a.) Pembagian Subcatchment

Langkah awal dalam penggunaan SWMM adalah pembagian subcatchment berdasarkan pada area penelitian. Pembagian tersebut dilakukan berdasarkan pada elevasi lahan dan pergerakan limpasan ketika terjadi hujan

b.) Pembuatan Model Jaringan

Pembuatan model jaringan dilakukan berdasarkan sistem jaringan drainase yang ada di lapangan. Model jaringan ini terdiri dari subcatchment, node junction, conduit, outfall node, dan rain gauge. Setelah model jaringan diperoleh, selanjutnya dimasukkan semua nilai parameter yang dibutuhkan untuk semua properti tersebut. Series

c.) Simulasi Respon Aliran pada Time

Simulasi respon aliran pada time series dilakukan untuk melihat respon debit aliran terhadap waktu berdasarkan sebaran curah hujan. Nilai yang dimasukkan adalah nilai sebaran curah hujan terhadap waktu dengan total nilai sesuai dengan curah hujan rancangan hasil dari analisis hidrologi.

d) Simulasi model

Simulasi ini dilakukan setelah model jaringan drainase dan semua parameter berhasil dimasukkan. Simulasi dikatakan berhasil jika continuity error $<10 \%$. Dalam simulasi SWMM debit banjir dihitung dengan cara memodelkan suatu sistem drainase. Aliran permukaan per unit area $(Q)$ terjadi jika air yang ada didalam tanah mencapai maksimum dan tanah menjadi jenuh. Menurut Santya dan Haikhal (2007), nilai Q dapat dihitung dengan Persamaan (4). Selanjutnya limpasan yang terjadi (Q) akan mengalir melalui conduit atau saluran yang ada.

$$
\begin{aligned}
& \mathrm{Q}=\mathrm{W} \mathrm{l} / \mathrm{n}(\mathrm{d}-\mathrm{dp})^{2 / 3} \mathrm{~S}^{1 / 2} \\
& \text { Keterangan: } \\
& \mathrm{Q}=\text { debit aliran yang terjadi }\left(\mathrm{m}^{3} / \text { det }\right) \\
& \mathrm{W}=\text { lebar subcatchment }(\mathrm{m}) \\
& \mathrm{n}=\text { koefisien kekasaran } \\
& \mathrm{Manning} \mathrm{d}=\text { kedalaman } \operatorname{air}(\mathrm{m}) \\
& \mathrm{dp}=\text { kedalaman air tanah }(\mathrm{m}) \\
& \mathrm{S}=\text { kemiringan subcatchment }
\end{aligned}
$$$$
\text { e.) Output SWMM }
$$

Output dari simulasi ini antara lain runoff quantity continuity, flow routing continutiy, highest flow instability indexes, routing time step, subcatchment runoff, node depth, node inflow, node surcharge, node flooding, outfall loading, link flow, dan conduit surcharge yang disajikan dalam laporan statistik simulasi rancangan.

\section{f.) Visualisasi hasil \\ Visualisasi hasil yang ditampilkan} berupa jaringan saluran drainase hasil output dari simulasi, profil aliran dari beberapa saluran utama dan yang diketahui tergenang, dan grafik aliran yang terjadi pada saluran.

\section{HASIL DAN PEMBAHASAN}

\section{Keadaan Umum Perumahan Alam Sinar Sari}

Perumahan Alam Sinar Sari terletak di Desa Sinar Sari dan secara administratif merupakan bagian dari wilayah Kecamatan Dramaga, Kabupaten Dramaga, Bogor. Di bagian tenggara dari perumahan tersebut, terletak Situ Ciranji 
yang merupakan salah satu tempat pengaliran limpasan (outlet). Perumahan ini merupakan perumahan yang sudah cukup lama terbangun dan ditempati oleh warga. Total luas dari perumahan berdasarkan peta masterplan terakhir sebesar 15 ha. Namun seiring berjalannya waktu dan pertumbuhan penduduk, keadaan di lapangan menunjukkan bahwa telah terjadi perubahan dimana adanya pertambahan bangunan dan infrastruktur yang tidak tertera pada peta masterplan sehingga pengamatan di lapang lebih lama dari yang seharusnya. Pada Tabel 4 dapat dilihat rencana penggunaan lahan yang tersedia pada peta masterplan.

Daerah Perumahan Alam Sinar Sari memilki ketinggian yang berkisar antara 194-205 m dpl. Kontur dari daerah ini relatif datar dengan kemiringan sebagian besar antara $1-8 \%$. Pada lokasi yang diamati, titik tertinggi adalah bagian jalan utama dan titik terendah terletak di titik outlet 1. Berdasarkan pengamatan lapangan, persentase lahan terbangun lebih banyak daripada lahan bervegetasi, sehingga air hujan yang terinfiltrasi ke tanah sedikit dan sisanya menjadi limpasan. Pola jaringan drainase dibagi menjadi dua tipe yaitu natural system dan paralel grid system (Feyen 1980).

Berdasarkan pengamatan, saluran drainase eksisting yang ada pada Perumahan Alam Sinar Sari termasuk tipe parallel grid system. Saluran drainase pada perumahan ini berbentuk persegi. Saluran yang dipakai terbuat dari beton dan nilai Manning yang digunakan adalah 0.014.

\section{Evaluasi Saluran Drainase dengan Model SWMM 5.1}

Perumahan Alam Sinar Sari memiliki luas sebesar 15 ha dengan total rumah terbangun sebanyak kurang lebih 350 rumah. Dari luas total 15 ha ini, kemudian dibagi menjadi banyak subcatchment. Pembagian subcatchment ini berdasarkan arah aliran saat terjadi runoff. Proses pembagian subcatchment, peletakan titik node dan penggambaran conduit pada aplikasi EPA SWMM 5.1 menggunakan citra satelit yang diperoleh dari aplikasi ArcGIS dengan data dari ESRI, HERE, DeLome, dan Mapmy India dengan pengambilan citra tanggal 25 Mei 2018 yang dapat dilihat pada Gambar 2. Selain menggunakan citra satelit, penggambaran sistem drainase juga mengikuti peta topografi yang dapat dilihat pada Gambar 3.

Tabel 4 Rencana Keseluruhan Penggunaan Lahan

\begin{tabular}{lcc}
\hline \multirow{2}{*}{ Keterangan } & \multicolumn{2}{c}{ LUAS } \\
\cline { 2 - 3 } & (ha) & $\%$ \\
\hline Lahan Efektif & 9.00 & 60.00 \\
Jalan & 4.19 & 27.96 \\
Fasilitas Sosial dan Umum & 1.81 & 12.04 \\
\hline TOTAL & 15 & 100 \\
\hline
\end{tabular}




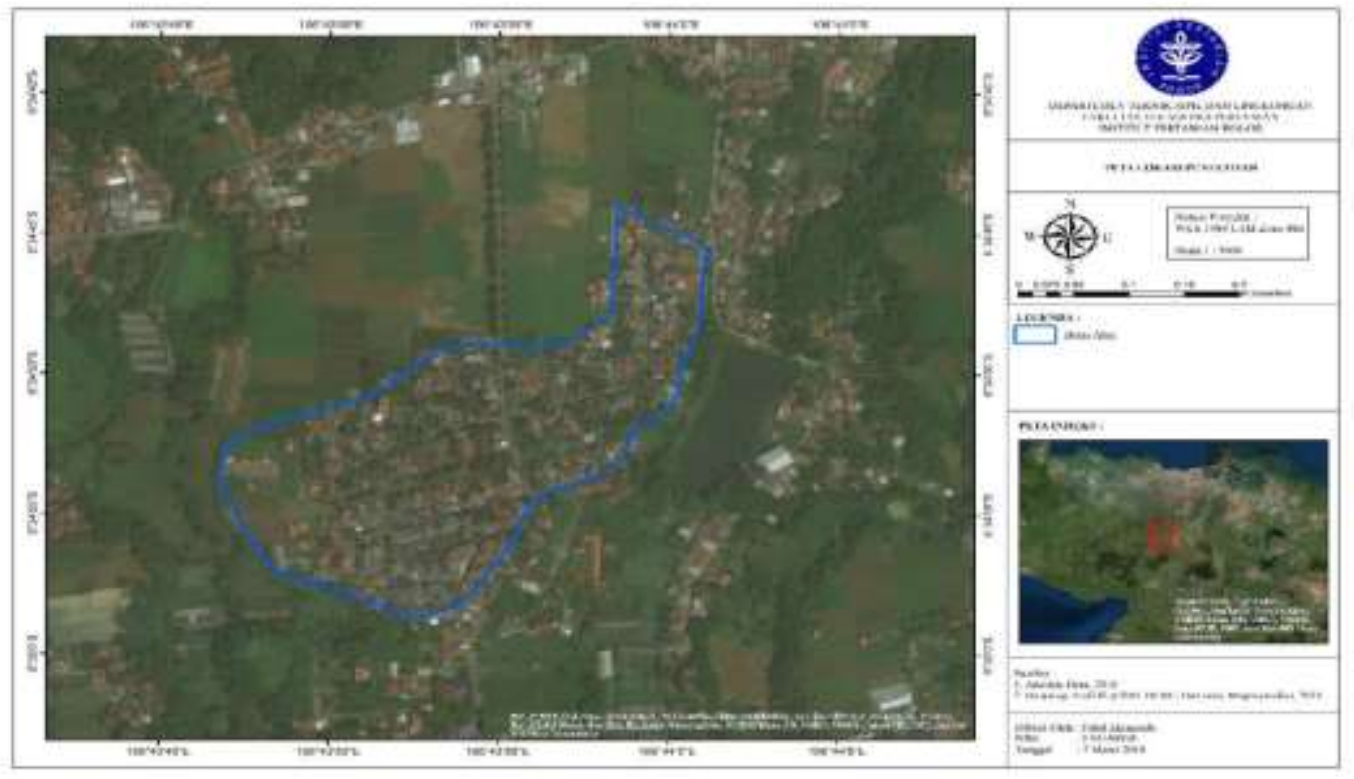

Gambar 2 Foto satelit lokasi

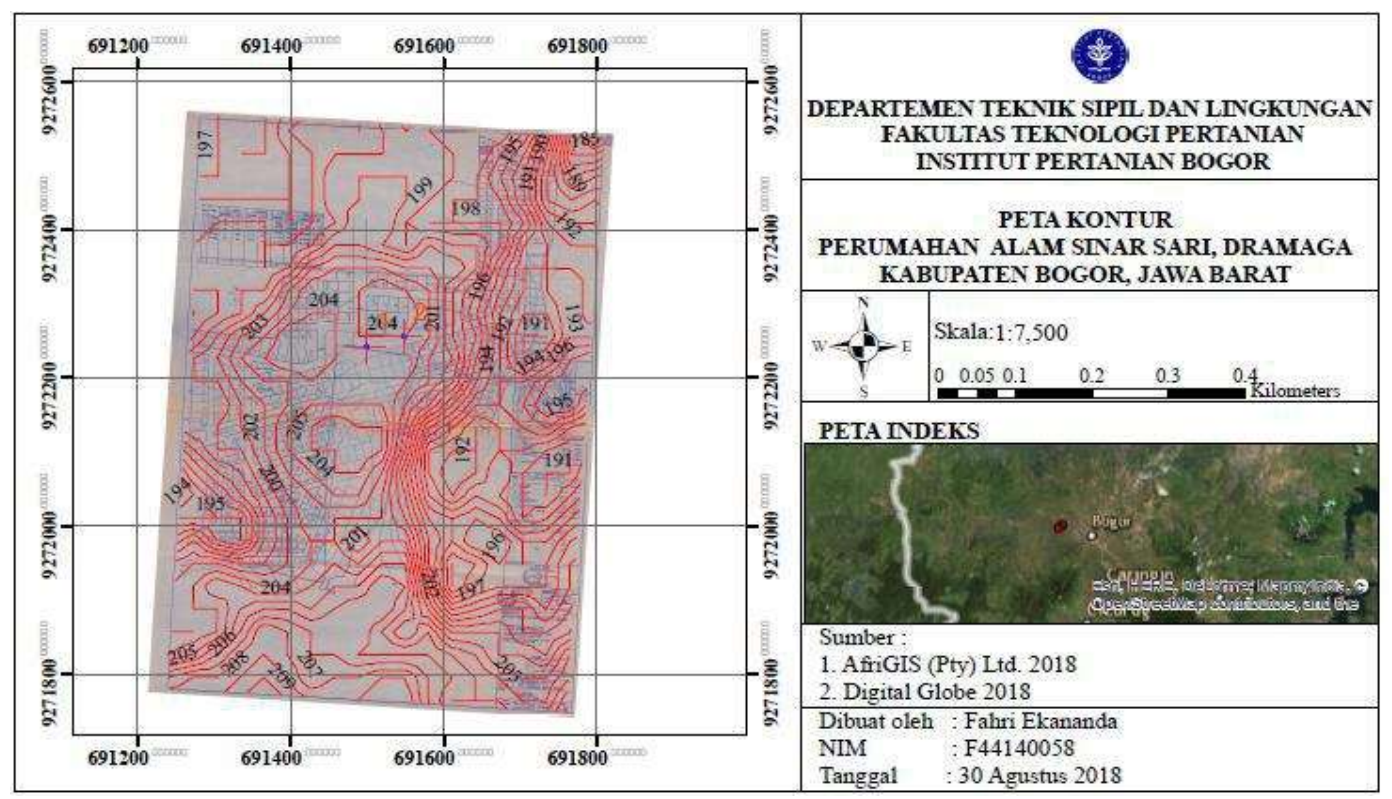

Gambar 3 Peta masterplan dengan kontur lahan 
Jika membandingkan peta masterplan terkahir yang dikeluarkan pihak perencana perumahan dengan kondisi yang di lapangan saat ini, ada beberapa lokasi dari perumahan yang berbeda. Hal ini disebabkan oleh semakin bertambahnya penduduk yang tinggal di daerah ini sehingga menyebabkan kebutuhan tempat tinggal juga ikut meningkat.

Sistem jaringan drainase dimodelkan menggunakan EPA SWMM 5.1, komponen yang diperlukan yaitu subcatchment, junction, conduit dan outfall. Setelah pemodelan didapatkan 69 subcatchment, 126 junctions, 158 conduits dan 3 outfalsl. Kondisi Perumahan Alam Sinar Sari merupakan perumahan padat penduduk. Selain pemukiman penduduk, lahan juga diperuntukkan untuk taman dan lapangan olahraga. Setiap blok rumah bisa terdiri dari satu atau dua subcatchment tergantung pada saluran yang ada di sekitarnya. Luas tiap subcatchment yang telah dibuat beragam.

Air hujan pada subcatchment yang memiliki nilai impervious tinggi akan mengalir dan sebagian besar akan menjadi limpasan karena tidak terserap tanah. Air limpasan dari tiap subcatchment akan mengalir ke junction. Junction berfungsi mengumpulkan air limpasan dan menampungnya sebelum dialirkan ke conduit. Conduit akan meneruskan aliran air yang diterima junction sebelumnya, conduit juga akan bertemu dengan junction berikutnya yang menjadi titik temu antar saluran. Nilai kemiringan tiap conduit bergantung pada panjang saluran dan juga elevasi pada junction. Data yang dipakai untuk rain gage yaitu $175.86 \mathrm{~mm}$ sesuai dengan curah hujan rencana. Pemodelan jaringan drainase dapat dilihat pada Gambar 4.

Data yang diperlukan pada subcatchment antara lain adalah luas subcatchment, luas pervious dan impervious lahan dan kemudian pada akhirnya dengan nilai hujan rencana akan menghasilkan parameter debit limpasan untuk subcatchment. Sedangkan parameter yang diperlukan untuk simulasi saluran adalah dimensi saluran seperti panjang, lebar, dan kedalaman serta slope saluran yang dimasukkan pada node. Kemudian setelah simulasi diperoleh parameter seperti kapasitas saluran dan kecepatan aliran. Pada simulasi ini, parameter yang diteliti adalah kapasitas dari saluran.

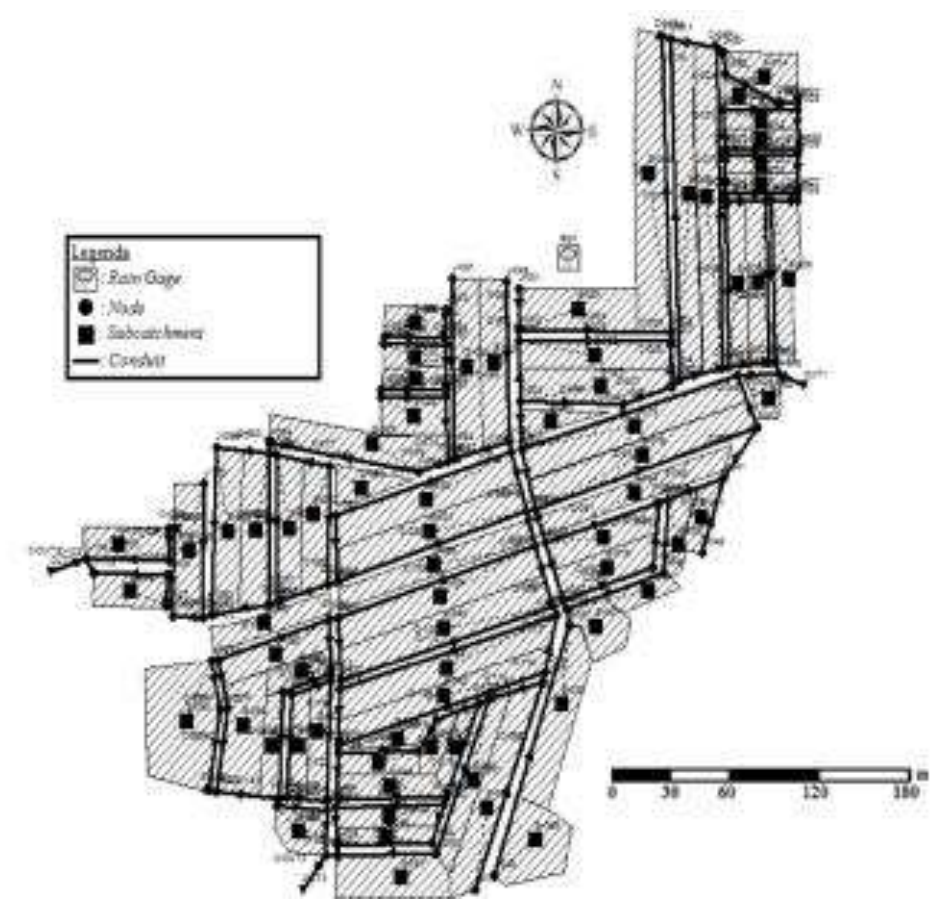

Gambar 4 Pemodelan jaringan drainase 
Nilai curah hujan rencana yang telah ditetapkan selanjutnya disimulasikan pada Time Series. Simulasi pada Time Series menggunakan pola distribusi hujan 6 jam. Pola distribusi 6 jam ini menggunakan metode hidrograf dengan alternating block method (Triatmodjo 2010). Sebaran distribusi hujan serta nilai curah hujan rencana yang disimulasikan pada time series disajikan pada Tabel 5.

Tabel 5 Distribusi Hujan Rencana

\begin{tabular}{lllllll}
\hline Waktu (jam ke-) & 1 & 2 & 3 & 4 & 5 & 6 \\
\hline Distribusi Hujan (\%) & 6.75 & 10.03 & 55.03 & 14.30 & 7.99 & 5.90 \\
Curah hujan rencana (mm) & 11.86 & 17.65 & 96.78 & 25.15 & 14.05 & 10.37 \\
\hline
\end{tabular}

Selanjutnya dilakukan simulasi respon aliran air. Apabila nilai continuity error untuk limpasan dan penelusuran aliran yang dihasilkan dari simulasi $<10 \%$, maka simulasi tersebut ternilai cukup baik. Jika tidak, maka analisis dianggap tidak berhasil atau nilainya diragukan (Rossman 2004). Nilai simulasi ini dibawah $<10 \%$ sehingga simulasi dianggap berhasil. Berdasarkan simulasi hujan sebesar $175.8 \mathrm{~mm}$, sebagian dari air hujan akan diserap dan sebagian lagi mengalir sebagai limpasan menuju saluran drainase.

Arah aliran pada sistem saluran drainase terbagi menjadi dua, yaitu ke kiri dimana aliran limpasan menuju sebuah kali yang nantinya bermuara ke sungai Cihideung dan ke kanan, dimana aliran limpasan akan menuju sebuah setu, yaitu Setu Ciranji. Pola aliran keseluruhan saluran perumahan dapat dilihat pada Gambar 5.

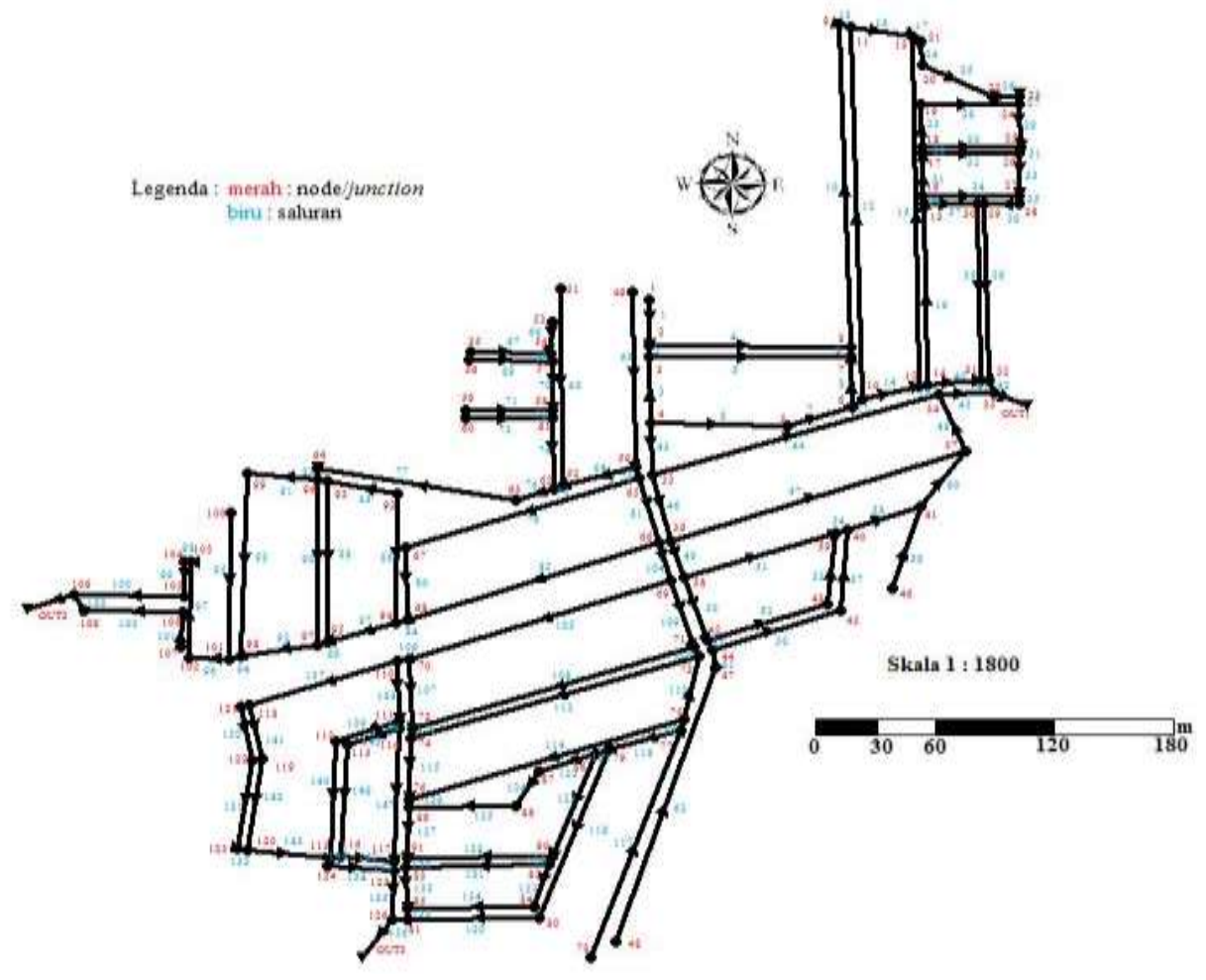

Gambar 5 Pola aliran keseluruhan saluran drainase

Sebagai contoh pergerakan pola aliran, akan diambil contoh salah satu subcatchment dengan node dan saluran yan ada di sekitarnya. Diantara node J104 dan node J105 terdapat saluran C99 dan kemudian debit dari saluran C99 menjadi debit dari saluran C100. Namun pada saluran C100 juga ikut mendapat limpasan 
dari subcatchment S37, dimana S37 dengan luas 0.09 ha menghasilkan debit limpasan sebesar $0.02 \mathrm{~m} 3 /$ detik sehingga debit limpasan C100 lebih besar daripada saluran C99. Debit saluran di C99 sebesar $0.098 \mathrm{~m} 3 /$ detik sedangkan di C100 sebesar $0.117 \mathrm{~m} 3 /$ detik. Selanjutnya debit limpasan pada $\mathrm{C} 100$ akan mengalir menuju saluran COUT2 yang terletak diantara node J106 dan OUT2 (outfall node). Pada Gambar 6 dapat dilihat hasil simulasi.

Berdasarkan hasil simulasi pada EPA SWMM 5.1, terdapat beberapa warna pada gambar. Warna biru tua, biru muda, hijau dan kuning menunjukkan bahwa tidak ada masalah. Namun warna merah berarti bahwa saluran melebihi kapasitas sehingga terjadi limpasan. Saluran melimpas dikarenakan debit rencana saluran lebih besar dibandingkan debit kapasitas saluran tersebut. Berdasarkan simulasi, saluran yang bermasalah sehingga berwarna merah adalah saluran C76, dimana besar debit rencana saluran lebih besar dibandingkan debit kapasitas saluran yaitu $0.088 \mathrm{~m} 3 /$ detik berbanding dengan $0.069 \mathrm{~m} 3 /$ detik yang artinya saluran tersebut mengalami limpasan sehingga harus dievaluasi.

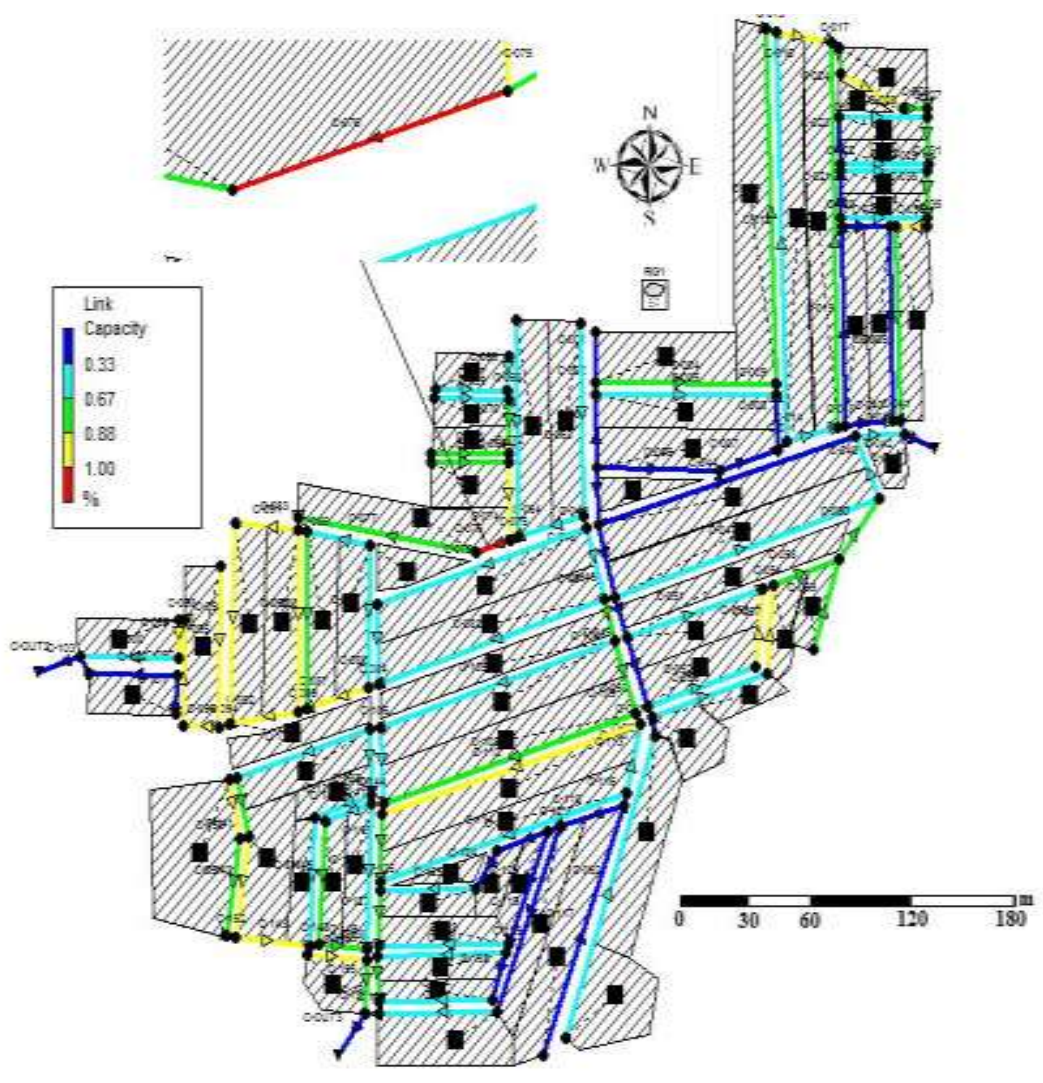

Gambar 6 Hasil simulasi EPA SWMM 5.1

Kecepatan aliran terkecil terjadi pada saluran C1 yaitu sebesar $0.04 \mathrm{~m} /$ detik sedangkan kecepatan aliran terbesar terjadi pada saluran COUT1 sebesar 3.62 m/detik. Secara umum kecepatan aliran yang diperbolehkan untuk saluran drainase perumahan adalah minimum sebesar 0.6 $\mathrm{m} /$ detik hingga maksimum $3.0 \mathrm{~m} /$ detik. Berdasarkan simulasi, saluran yang tidak memenuhi batas minimum kecepatan aliran adalah saluran $\mathrm{C} 1, \mathrm{C} 2, \mathrm{C} 3, \mathrm{C} 8, \mathrm{C} 12, \mathrm{C} 23$, C28, C30, C32, C34, C37, C43, C50, C59, C63, C64, C66, C67, C69, C70, C71, C73, C78, C85, C86, C95, C104, C107, C109, C118, C119, C131, C134, C139, C140, C141, C145, C146, dan C154 sedangkan saluran yang melebihi batas maksimum kecepatan aliran adalah C40, C41, C42, C45, dan COUT1. Ditentukan batas ini bertujuan untuk mengatasi sedimentasi jika 
dibawah kecepatan minimum dan menghindari penggerusan saluran ketika diatas kecepatan maksimum. Hal-hal yang dapat dilakukan untuk mengatasi masalah tersebut antara lain dengan cara perawatan rutin terkait sedimentasi saluran serta pengaturan slope saluran.

Evaluasi dilakukan agar saluran mampu menampung aliran air sehingga limpasan dapat dihindari. Menurut Mulya (2017), pembuatan dimensi saluran baru berupa penambahan lebar, tinggi, dan kemiringan dasar saluran sesuai pertimbangan keadaan lapangan dan perencanaannya. Gambar 7 menunjukkan profil aliran dari saluran $\mathrm{C} 75$ hingga $\mathrm{C} 76$.

Berdasarkan Gambar 7, dapat dilihat bahwa aliran air pada saluran C76 lebih tinggi daripada aliran air pada saluran C75. Berdasarkan simulasi, pada jam ke-3 limpasan dalam kondisi terbesar dikarenakan pada pembagian distribusi hujan rencana, jam ke-3 lah yang memiliki persentase hujan terbesar. Setelah itu, baru kemudian aliran air ikut menurun terhadap waktu kembali. Pada Gambar 8 dapat dilihat fluktuasi limpasan terhadap waktu pada saluran C76.

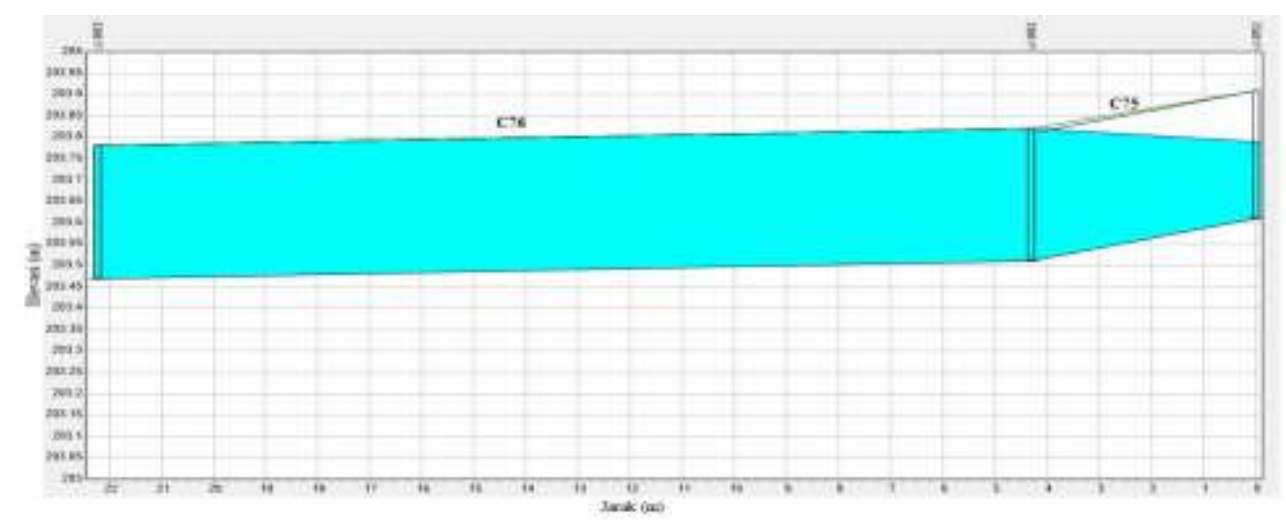

Gambar 7 Profil aliran C75-C76

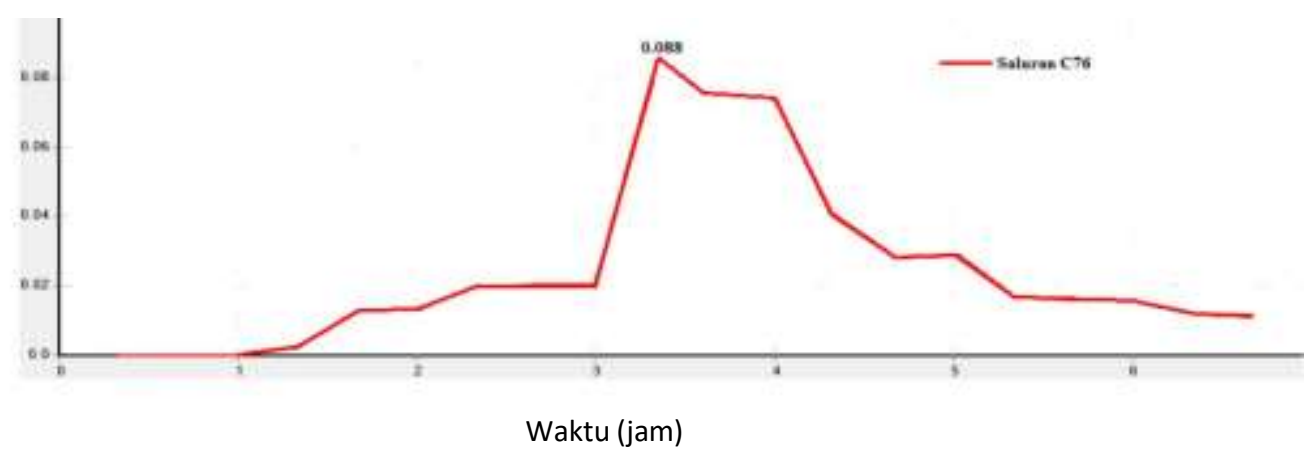

Gambar 8 Fluktuasi limpasan terhadap waktu

Perhitungan evaluasi berdasarkan penampang saluran terbaik dimana penampang saluran memiliki keliling basah minimum dan saluran mampu menampung aliran air. Dari hasil evaluasi, aluran C76 disarankan untuk diubah lebarnya dari 0.34 $\mathrm{m}$ menjadi $0.50 \mathrm{~m}$. Kemudian dimensi baru dari saluran C76 dimasukkan ke dalam simulasi EPA SWMM 5.1 lagi dan hasil simulasinya disajikan pada Gambar 9. Pada
Gambar 9 sudah tidak terlihat saluran berwarna merah, artinya saluran C76 sudah memadai kapasitasnya.

Gambar 10 memperlihatkan profil aliran dan fluktuasi limpasan saluran C76. Setelah saluran dievaluasi saluran dapat menampung aliran sehingga tidak terjadi limpasan sehingga keseluruhan sistem dapat bekerja dengan baik dan tidak menimbulkan limpasan. 


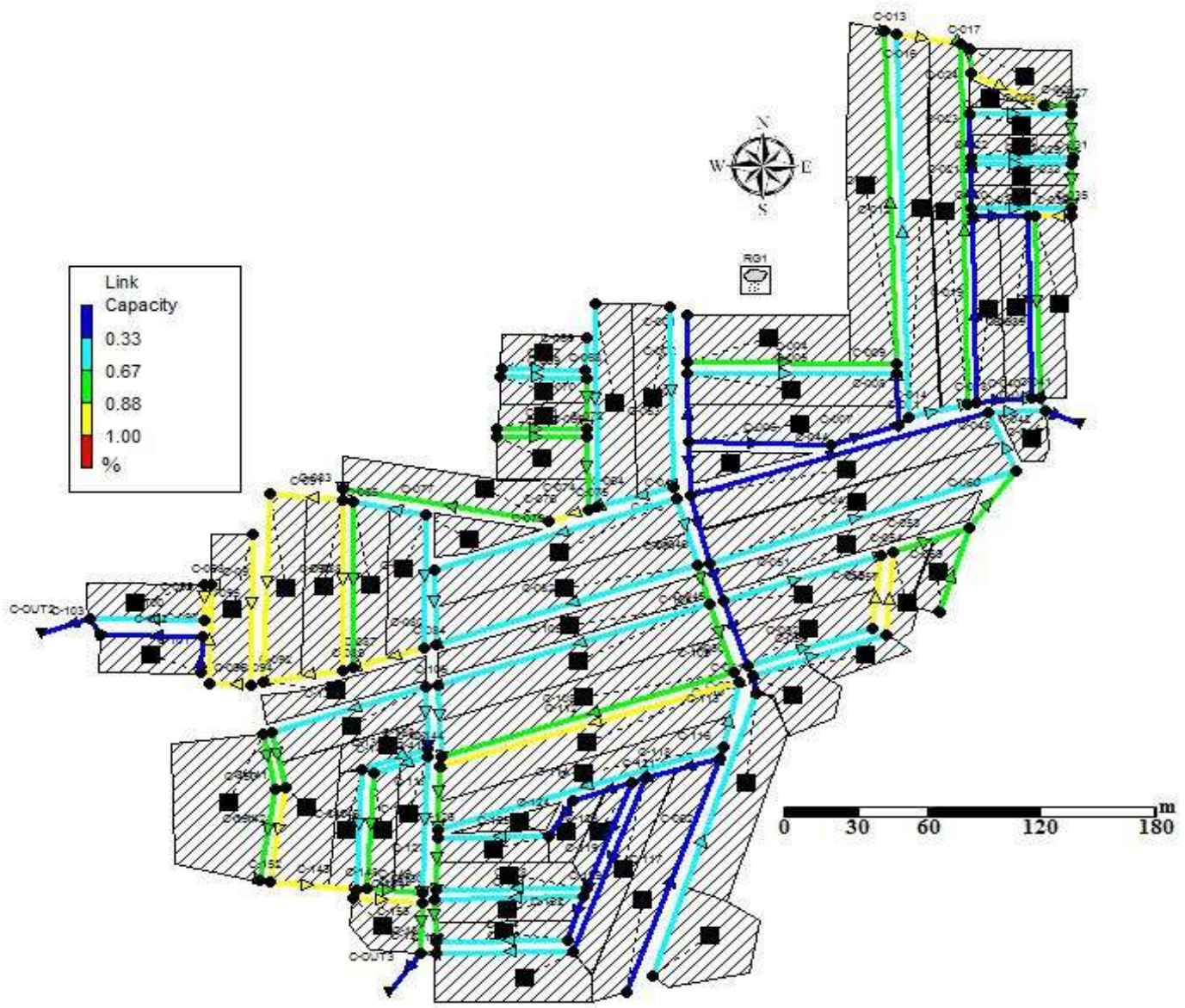

Gambar 9 Hasil simulasi setelah perbaikan

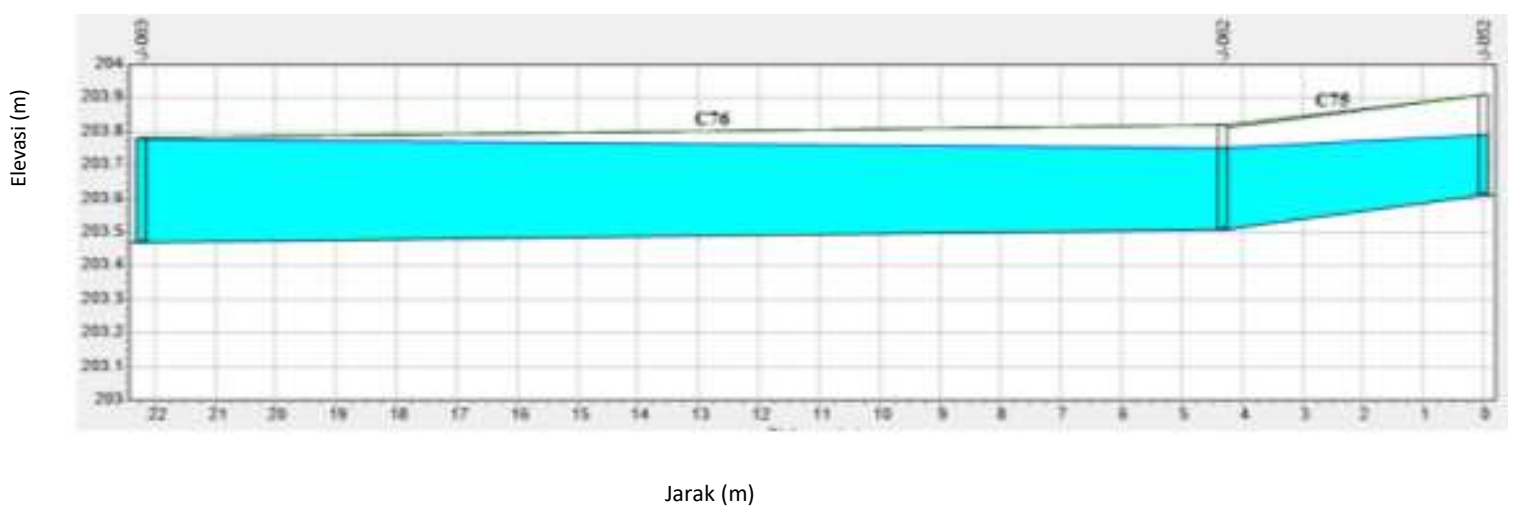

Gambar 10 Profil aliran C76 setelah perbaikan

\section{SIMPULAN}

Kondisi saluran drainase pada Perumahan Alam Sinar Sari berdasarkan hasil pengamatan mampu mengalirkan air dengan baik, namun dibeberapa titik terdapat penyumbatan dan sedimentasi serta kurang perawatan. Jika terjadi hujan besar, terkadang terjadi limpasan yang membuat jalan dan daerah di sekitar saluran yang bermasalah menjadi tergenang. Setelah dilakukan simulasi, Perumahan Alam Sinar Sari terdiri atas 69 subcatchment, 126 junction, 158 conduit dan 3 outfall. Saluran yang bermasalah akan ditandai dengan warna merah yang disebabkan oleh debit rancangan saluran melebihi debit kapasitasnya. Berdasarkan hasil simulasi pada EPA SWMM 5.1, saluran bermasalah yaitu saluran C76 dimana tidak memadai 
kapasitasnya sehingga terjadi limpasan. Debit kapasitas dari saluran C76, yaitu sebesar $0.088 \mathrm{~m}^{3} /$ detik lebih besar dibandingkan debit rencana yang hanya sebesar $0.069 \mathrm{~m}^{3} /$ detik. Setelah dilakukan evaluasi, saluran C76 disarankan dilakukan perubahan dimensi lebar dari $0.34 \mathrm{~m}$ menjadi $0.50 \mathrm{~m}$ agar saluran mampu menampung limpasan.

\section{DAFTAR PUSTAKA}

Babbit HE. 1969. Sewage and Sewerage Treatment Plant. New York (US) : McGraw Hill.

Dewi IAA, Arsana IK, Suputra IA. 2013. Analisis Kapasitas Saluran Drainase Sekunder dan Penanganan Banjir di Jalan Gatot Subroto Denpasar. Jurnal Ilmiah Elektronik Infrastruktur Teknik Sipil. 2(2): 151-155.

Feyen J. 1980. Drainage of Irrigated Land. London (UK): Batsford Academic and Educatonial Ltd, Katholieke Universitet Leuven, Center for Irrigation Engineering.

Hasmar HHA. 2011. Drainase Terapan. Yogyakarta (ID): UII Press.

Luciana RF, Edijatno, Sofia F. 2013. Analisa Sistem Drainase Saluran Kupang Jaya akibat Pembangunan Apartemen Puncak Bukit Golf di Kota Surabaya. Jurnal Teknik Pomits. 1(1): 1-5.

Mulya RA. 2017. Evaluasi Saluran Drainase Dengan Menggunakan Program SWMM 5.1 di Perumahan De Bale Permata Arcadia, Depok, Jawa Barat (skripsi). Bogor (ID). Institut Pertanian Bogor.

Rossman L. 2004. Storm Water Management Model User's Manual Version 5.0. Cincinnati (US) : EPA United Stated Environmental Agency.

Santya SR, Haikhal TN. 2007. Pengembangan

Saluran Drainase Kawasan Bandar Udara Achmad Yani [skripsi]. Semarang (ID) : Fakultas Teknik Universitas Diponegoro.

Tangkudung H, Kawet L, Wuisan EM, Pania HG. 2013. Perencanaan Sistem Drainase Kawasan Kampus Universitas Sam Ratulangi. Jurnal Sipil Statik. 1(3): 164170.

Triatmodjo B. 2010. Hidrologi Terapan. Yogyakarta (ID): Beta Offset. 
